\section{BRAZIULIAN JOURNAL}

OF MEDICAL AND BIOLOGICAL RESH.ARCH

www.bjournal.com.br
ISSN 0100-879X

Volume 43 (03) 226-324 March 2010

BIOMEDICAL SCIENCES

AND

CLINICAL INVESTIGATION

Braz J Med Biol Res, March 2010, Volume 43(3) 226-229

Implications of infectious diseases and the adrenal hypothesis for the etiology of childhood acute lymphoblastic leukemia

F. Azevedo-Silva, B. de Camargo and M.S. Pombo-de-Oliveira

The Brazilian Journal of Medical and Biological Research is partially financed by
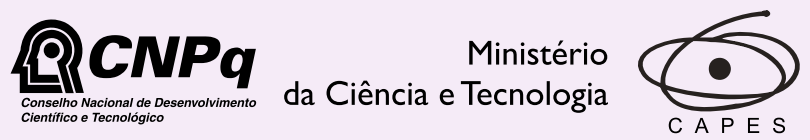

Ministério da Educação

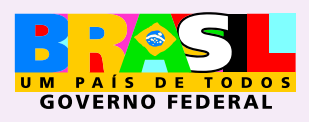

Institutional Sponsors 


\title{
Implications of infectious diseases and the adrenal hypothesis for the etiology of childhood acute lymphoblastic leukemia
}

\author{
F. Azevedo-Silva, B. de Camargo and M.S. Pombo-de-Oliveira \\ Programa de Hematologia e Oncologia Pediátricos, Centro de Pesquisa, \\ Instituto Nacional de Câncer, Rio de Janeiro, RJ, Brasil
}

\begin{abstract}
Acute leukemia is the most frequent cancer in children. Recently, a new hypothesis was proposed for the pathogenesis of childhood acute lymphoblastic leukemia (ALL). The so-called "adrenal hypothesis" emphasized the role of endogenous cortisol in the etiology of B-cell precursor ALL. The incidence peak of ALL in children between 3 to 5 years of age has been well documented and is consistent with this view. The adrenal hypothesis proposes that the risk of childhood B-cell precursor ALL is reduced when early childhood infections induce qualitative and quantitative changes in the hypothalamus-pituitary-adrenal axis. It suggests that the increased plasma cortisol levels would be sufficient to eliminate all clonal leukemic cells originating during fetal life. Because Brazil is a continental and tropical country, the exposure to infections is diversified with endemic viral and regionally non-viral infections, with some characteristics that support the recent adrenal hypothesis. Here we discuss this new hypothesis in terms of data from epidemiological studies and the possible implications of the diversity of infections occurring in Brazilian children.
\end{abstract}

Key words: Lymphoblastic leukemia; Childhood infections; Epidemiology; Kala-azar; Adrenal hypothesis

In a recent publication Schmiegelow et al. (1) proposed the important role of plasma cortisol level in the etiology of common-acute lymphoblastic leukemia (c-ALL), which they called "adrenal hypothesis". This hypothetical etiology of c-ALL emerged from several lines of evidence obtained from descriptive epidemiological data around the world (2), and from clinical evidence of the mechanism of adrenocorticotropic hormone therapy (3). Most of the current data supporting the role of infections in the pathogenesis of C-ALL have considered the presence of peak in the incidence of c-ALL in 3- to 5-year-old children from developed countries with high standards of hygiene $(2,4)$. The combination of ethnic homogeneity, free and easily accessible public health care, and unparalleled registration of all children diagnosed with leukemia has made the Nordic countries an excellent setting to test the hypothesis that supports the protective role of infections in c-ALL pathogenesis (5). Infections can stimulate the hypothalamus-pituitary-adrenal axis, leading to increased plasma cortisol levels sufficient to eliminate clonal leukemic cells originating during fetal life (1).

Only a few studies with immunophenotyping tests have been subjected to epidemiological analysis in developing countries (6). Currently, a different scenario is emerging, mainly in countries such as Brazil and Mexico, thus permitting international comparisons $(7,8)$. Since the year 2000 , there has been a remarkable improvement in the recognition of pediatric malignancies in Brazil. The development of a national program, which provides access to immunophenotype and molecular tests (7) and the development of Population-Based Cancer Registries (PBCR), have led to more reliable data to be used for health measures. In a series of 1690 ALL cases ascertained over a period of 8 years (2000-2007), c-ALL (Figure 1A) presented a smoother curve of age/frequency of B-cell precursor ALL (Bp-ALL) than that observed in developed countries and similar to that described in Mexico (8). Interestingly, when we compared the age-specific incidence rates and median incidence of acute leukemia during the reference period with data generated by the Brazilian PBCR, we observed the same curve shape (9).

Although access to health care has gradually improved the identification of pediatric malignancies, the scenario re-

Correspondence: M.S. Pombo-de-Oliveira, Programa de Hematologia e Oncologia Pediátricos, Centro de Pesquisa, Instituto Nacional de Câncer, Rua André Cavalcanti, 37, 20231-050 Rio de Janeiro, RJ, Brasil. Fax: +55-21-3233-1470. E-mail: mpombo@inca.gov.br

Received July 22, 2009. Accepted February 1, 2010. Available online February 19, 2010. Published March 12, 2010. 
garding age and incidence of ALL remains unchanged when we compare the present data with previous publications $(9,10)$. The age-peak profile today seems to be the same as a decade ago, supporting the assumption of Schmiegelow
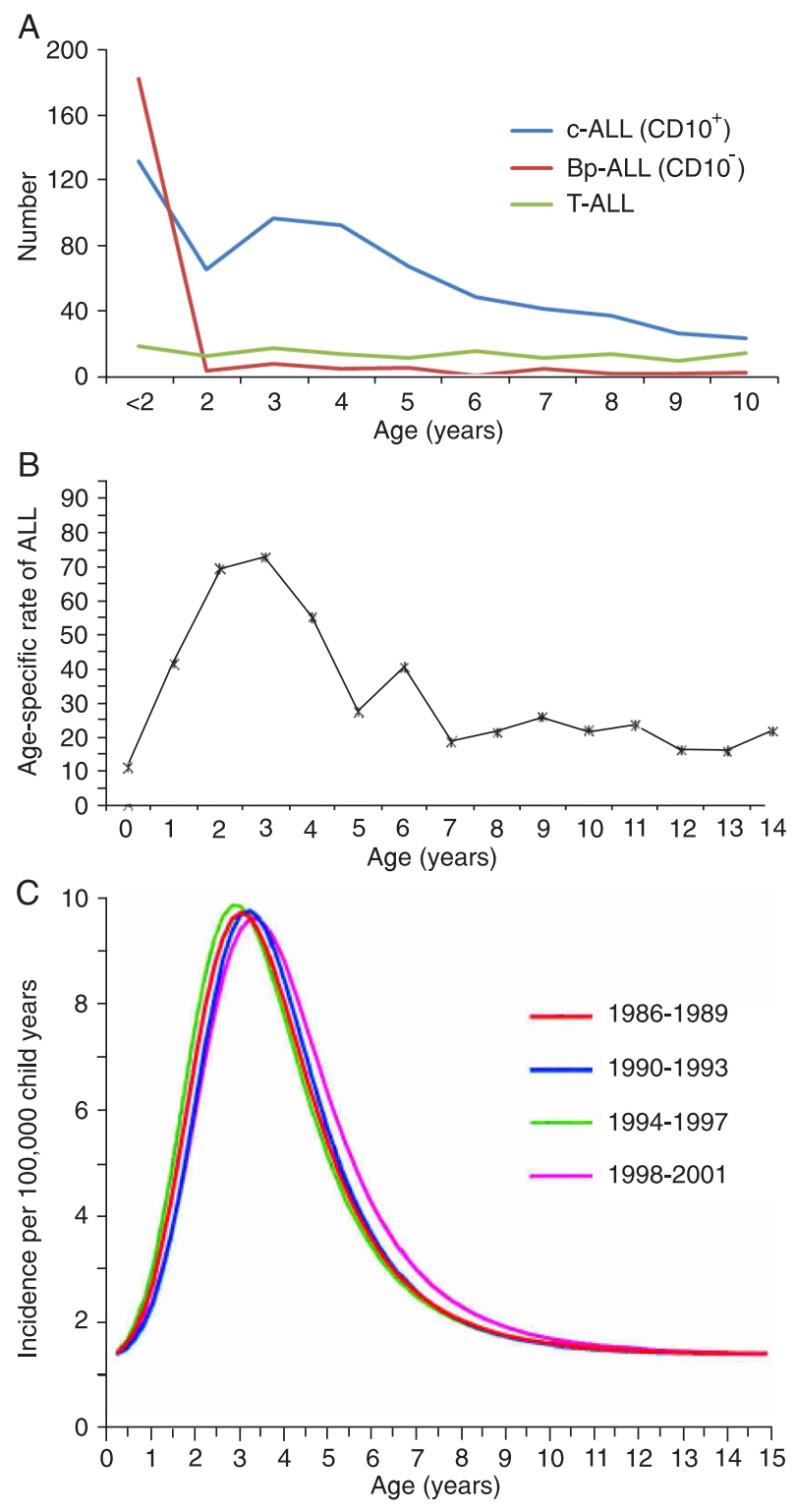

Figure 1. A, Distribution of age at diagnosis of a series of acute lymphoblastic leukemia (ALL) cases from Brazil, 2000-2007. Number of ALL cases $=1690 ; \mathrm{Bp}-\mathrm{ALL}=\mathrm{B}$-cell precursor ALL with CD10- $(\mathrm{N}=356)$; $\mathrm{C}-\mathrm{ALL}=$ common B-cell precursor ALL $\left(\mathrm{CD} 10^{+}\right.$, $\mathrm{N}=1069) ; \mathrm{T}-\mathrm{ALL}=\mathrm{T}$-cell ALL $(\mathrm{N}=284)$. Data source: Hospitalbased ascertained cases (Ref. 7). $B$, Age-specific incidence rates of 16 Brazilian cases of ALL from the Populational-Based Cancer Registry (PBCR) (modified from Ref. 12). C, Age-specific incidence rates of Bp-ALL. Model-predicted age-specific incidence rates of Bp-ALL in Nordic countries (reproduced with permission from Ref. 5, Oxford University Press). et al. (1) that the lower registration of childhood ALL is not simply the result of underreporting or misdiagnosis notifications. This dataset analysis has also demonstrated that there was a 3-fold increase in the diagnosis of acute leukemia from 2000-2007 compared to 1990-1999 (7). Immunophenotyping and molecular tests were performed in order to evaluate whether the biomarkers would differ according to age, skin color and residence regions. Presently, Bp-ALL accounts for $59 \%(\mathrm{~N}=1425)$ of the total ALL cases, with a similar pattern of subtype distribution in various geographical regions (7). In this series of Bp-ALL cases, we observed that $18.7 \%$ of $c-A L L$ cases $(N=812)$ harbored ETV6-RUNX1 gene fusion. This frequency is similar to that reported in a small series of Bp-ALL and slightly lower than that usually reported in developed countries, i.e., 25 to $30 \%$ of c-ALL cases (11). Data analysis from PBCRs representative of the 5 different regions of Brazil demonstrated that the incidence rate of ALL could differ regionally (Table 1). For instance, the mean rate of childhood leukemia incidence adjusted by age demonstrated higher rates for both males and females in Curitiba (Southeast of Brazil) and Goiânia (Center-West), whereas the lowest rates were detected in Salvador and Aracaju (Northeast) (12). The populations at risk in the geographical regions where the PBCR are located are socially and economically distinct. Because childhood leukemia must be treated in a specialized care unit, we cannot rule out that leukemia occurring in populations of low-income status could be underreported or misdiagnosed. Therefore, we have recently demonstrated that underreported cases could also vary between PBCRs (13).

Because Brazil is a continental and tropical country, exposure to infection varies, with the presence of endemic viral and regionally non-viral infections with some characteristics that hypothetically support the recent Schmiegelow's hypothesis (1). These differences of incidence rate in Brazil could be explained by early exposure to different kinds of infections, and a possible continuous level of cortisol secretion that could eliminate abnormal leukemic clones in children living in areas of persistent exposure to infectious agents. It is true that socio-economic levels as confounding factors can impair the understanding of boundaries among different environmental risk factors associated with ALL. Sanitation and vaccination have gradually improved in different areas of Brazil, possibly explaining the high incidence of childhood ALL in more developed cities. A recent study by Ribeiro et al. (14) revealed that in São Paulo city (Southern region), poverty districts tend to have a smaller number of cases of childhood ALL.

Although infant mortality in Brazil has decreased as a whole, inequalities still exist across the country and the Northeast region has higher rates of poor housing conditions with deficient sanitation. In 2005, the overall leading causes of inpatient morbidity were respiratory diseases (42.2\%) followed by infectious diseases $(27.1 \%)$ in children aged 1 to 4 years (http://w3.datasus.gov.br). Regarding vector- 
Table 1. Incidence rate of acute lymphoblastic leukemia in 14 PBCR-Brazil, 2008.

\begin{tabular}{|c|c|c|c|c|c|c|c|}
\hline \multirow[t]{2}{*}{ PBCR } & \multirow[t]{2}{*}{ Period } & \multicolumn{5}{|c|}{ Incidence rate per million by age in both males and females } & \multirow{2}{*}{$\begin{array}{c}\text { Age-standardized } \\
\text { rate (per million) }\end{array}$} \\
\hline & & 0-11 months & $1-4$ years & $5-9$ years & $10-14$ years & $15-18$ years & \\
\hline Curitiba, PR & $1998-2002$ & 15.3 & 85.2 & 57.8 & 26.8 & 24.0 & 48.3 \\
\hline Porto Alegre, RS & 1998-2002 & 19.1 & 59.0 & 34.8 & 17.9 & 12.1 & 31.5 \\
\hline São Paulo, SP & 1998-2002 & 18.6 & 50.0 & 31.2 & 26.2 & 18.1 & 31.5 \\
\hline Belo Horizonte, MG & $2000-2003$ & 14.3 & 55.7 & 35.1 & 27.4 & 17.8 & 43.1 \\
\hline Jaú, SP & $2000-2004$ & - & 145.0 & 22.1 & - & 22.2 & 46.4 \\
\hline Recife, PE & $1997-2001$ & 17.3 & 69.8 & 32.0 & 44.0 & 15.5 & 40.3 \\
\hline Natal, RN & 1998-2001 & - & 67.7 & 18.7 & 30.5 & 16.1 & 32.1 \\
\hline João Pessoa, PB & $2000-2004$ & - & 37.1 & 21.4 & 13.0 & 26.0 & 23.0 \\
\hline Aracaju, SE & $1996-2000$ & 25.0 & 44.6 & 18.9 & 12.4 & 9.5 & 22.5 \\
\hline Fortaleza, CE & 1998-2002 & 9.6 & 36.6 & 24.6 & 19.6 & 11.7 & 23.1 \\
\hline Salvador, BA & 1998-2002 & - & 24.3 & 17.3 & 10.0 & 8.0 & 14.5 \\
\hline Manaus, AM & 1999-2002 & 37.0 & 94.5 & 50.4 & 28.3 & 18.8 & 49.5 \\
\hline Distrito Federal & 1999-2002 & 4.8 & 37.5 & 24.9 & 17.0 & 4.4 & 21.1 \\
\hline Goiânia, GO & 1999-2003 & 32.6 & 64.5 & 57.4 & 27.5 & 33.5 & 46.1 \\
\hline
\end{tabular}

Source: Instituto Nacional de Câncer, MS, 2008 [www.inca.gov.br/tumores infantis/]; Refs. 9 and 12. PBCR = Populational-Based Cancer Registry. States of Brazil: PR = Paraná; RS = Rio Grande do Sul; SP = São Paulo; MG = Minas Gerais; PE = Pernambuco; $\mathrm{RN}=$ Rio Grande do Norte; $\mathrm{PB}=$ Paraíba; $\mathrm{SE}=$ Sergipe; $\mathrm{CE}=$ Ceará; $\mathrm{BA}=$ Bahia; $\mathrm{AM}=$ Amazonas; $\mathrm{GO}=\mathrm{Goiás}$.

borne diseases, in 1999, 632,600 new cases of malaria were recorded although malaria mortality was reduced from 0.7 to 0.1 deaths per 100,000 individuals. In 2006 , nearly 270,000 cases of dengue fever were reported. In 2006, nearly 4000 cases of visceral leishmaniasis and 23,583 cases of cutaneous leishmaniasis were reported. These types and severity of infections influence the disequilibrium of Th1/Th2 responses. Studies have demonstrated that Leishmania chagasi infection and the human immune response result in an asymptomatic clinical phase with a Th1-type immune response with hypersensitivity and a symptomatic period (Kala-azar) with a Th2 response characterized by hyposensitivity. Between these two stages of immune modulation, affected individuals can present an intermediate subclinical phase with undefined immunological characteristics $(15,16)$.

What is the correlation between this explanation and Schmiegelow's hypothesis? Quoting the study of Dunne and Cooke (17) about the consequence of the extended infectious disease burden and the adaptive effect of cytokine responses to IL-4, IL-10, and IL-12, the authors argue that an over-reactive inflammatory response is minimized by the anti-inflammatory effect of endogenous cortisol secretion and subsequently this cortisol action could eliminate the possible leukemic clone, this being the reason for the low incidence of C-ALL in malnourished children.

From our viewpoint, the understanding of the implications of such infectious diseases regarding acute leukemia, with intense stimulation of the immune system, and other environmental exposure of lymphoid cells would help to test Schmiegelow's hypothesis in Brazil.

In our experience diagnosing acute leukemia in samples of children living in endemic areas of $L$. chagasi infection, we found children in whom bone marrow aspiration analysis by flow cytometry identified a higher proportion of immature cells with a CD $19^{+} / \mathrm{CD} 10^{+} / \mathrm{CD} 38^{+}$profile compatible with cell proliferation status. Morphology, immuno-molecular and serological tests and, clinical follow-up of these patients excluded the diagnosis of acute leukemia. Thus, in 5 children, we detected a concomitant diagnosis of ALL and the presence of amastigote forms of $L$. chagasi in histiocytes (Azevedo-Silva F, Cordeiro SN, Vasconcelos GM, Souza CSF, Calabrese KS, Pombo-de-Oliveira MS, unpublished data). Whether a parasitic infection, or even Kala-azar treatment may play a role in the pathogenesis of acute leukemia remains to be tested.

To further explore and test this hypothesis we have analyzed data settings from endemic areas of Kala-azar (Salvador, Recife, João Pessoa). First of all, we reviewed the age-adjusted incidence rate of ALL by the method of capture and re-capture in order to include possible unreported ALL cases to the PBCRs (13); secondly, we are analyzing whether the magnitude of risk of serologically positive $L$. chagasi infection, as a proxy of previous exposure, may or may not be associated with c-ALL in these 3 cities (Azevedo-Silva F, Cordeiro SN, Vasconcelos GM, Souza CSF, Calabrese KS, Pombo-de-Oliveira MS, unpublished data); then, we began to evaluate the percentage 
of healthy newborns harboring ETV6/RUNX1-positive cord blood cells (as a risk of developing c-ALL) in order to test if associated factors may be related to the disappearance of such 'preleukemic' cells in infancy, and may influence the subsequent risk of ALL in settings like João Pessoa, State of Paraíba, and São Luis, State of Maranhão.

To sum up, the existing scientific data suggest that infection plays a critical role in the development of c-ALL, albeit no particular microbial agent is directly implicated. It is plausible that a high burden of severe and continuous infectious episodes may contribute to reducing childhood

\section{References}

1. Schmiegelow K, Vestergaard T, Nielsen SM, Hjalgrim H. Etiology of common childhood acute lymphoblastic leukemia: the adrenal hypothesis. Leukemia 2008; 22: 2137-2141.

2. Edgar K, Morgan A. Does infections cause or prevent childhood leukemia? A review of the scientific evidence. London: Children with Leukemia; 2008.

3. Gaynon PS, Carrel AL. Glucocorticosteroid therapy in childhood acute lymphoblastic leukemia. Adv Exp Med Biol 1999; 457: 593-605.

4. Greaves M. Infection, immune responses and the aetiology of childhood leukaemia. Nat Rev Cancer 2006; 6: 193-203.

5. Hjalgrim LL, Rostgaard K, Schmiegelow K, Soderhall S, Kolmannskog S, Vettenranta K, et al. Age- and sex-specific incidence of childhood leukemia by immunophenotype in the Nordic countries. J Natl Cancer Inst 2003; 95: 1539-1544.

6. Rego EM, Garcia AB, Viana SR, Falcao RP. Characterization of acute lymphoblastic leukemia subtypes in Brazilian patients. Leuk Res 1996; 20: 349-355.

7. Pombo de Oliveira MS, Koifman S, Vasconcelos GM, Emerenciano M, de Oliveira NC. Development and perspective of current Brazilian studies on the epidemiology of childhood leukemia. Blood Cells Mol Dis 2009; 42: 121-125.

8. Bernaldez-Rios R, Ortega-Alvarez MC, Perez-Saldivar ML, Alatoma-Medina NE, Del Campo-Martinez ML, RodriguezZepeda MC, et al. The age incidence of childhood B-cell precursor acute lymphoblastic leukemia in Mexico City. $J$ Pediatr Hematol Oncol 2008; 30: 199-203.

9. de Camargo B, Santos MD, Rebelo MS, Reis RD, Ferman $\mathrm{S}$, Noronha $\mathrm{CP}$, et al. Cancer incidence among children and adolescents in Brazil: First report of 14 populationbased cancer registries. Int J Cancer 2009; DOI 10.1002/
ALL due to endogenous cortisol secretion. Since these hypotheses remain to be proved, the evaluation of parasitic infections that directly affect the bone marrow environment should be tested in order to add another piece to the ALL pathogenesis puzzle.

\section{Acknowledgments}

M.S. Pombo-de-Oliveira is supported in part by a grantin-aid from CNPq (\#309091/2007-1) and INCA-FAF/Swiss Bridge Foundation (\#230150-4).

ijc.24799.

10. Parkin DM, Stiller CA, Draper GJ, Bieber CA. The international incidence of childhood cancer. Int J Cancer 1988; 42: 511-520.

11. Magalhaes IQ, Pombo-de-Oliveira MS, Bennett CA, Cordoba JC, Dobbin J, Ford AM, et al. TEL-AML1 fusion gene frequency in paediatric acute lymphoblastic leukaemia in Brazil. Br J Haematol 2000; 111: 204-207.

12. Reis RS, de Camargo B, Azevedo-Silva F, Ferreira JMO, Santos MO, Pombo-de-Oliveira MS. Childhood leukemia incidence in Brazil according to different geographical regions. Pediatric Blood and Cancer 2009 (in press).

13. Azevedo-Silva F, Reis RS, de Oliveira Santos M, Luiz RR, Pombo-de-Oliveira MS. Evaluation of childhood acute leukemia incidence and underreporting in Brazil by capturerecapture methodology. Cancer Epidemiol 2009; 33: 403405.

14. Ribeiro KB, Buffler PA, Metayer C. Socioeconomic status and childhood acute lymphocytic leukemia incidence in São Paulo, Brazil. Int J Cancer 2008; 123: 1907-1912.

15. Holaday BJ, Pompeu MM, Evans T, Braga DN, Texeira MJ, Sousa AQ, et al. Correlates of Leishmania-specific immunity in the clinical spectrum of infection with Leishmania chagasi. $J$ Infect Dis 1993; 167: 411-417.

16. Jeronimo SM, Teixeira MJ, Sousa A, Thielking P, Pearson RD, Evans TG. Natural history of Leishmania (Leishmania) chagasi infection in Northeastern Brazil: long-term follow-up. Clin Infect Dis 2000; 30: 608-609.

17. Dunne DW, Cooke A. A worm's eye view of the immune system: consequences for evolution of human autoimmune disease. Nat Rev Immunol 2005; 5: 420-426. 